\title{
Comparison of chemical compounds associated with sclerites from healthy and diseased sea fan corals (Gorgonia ventalina)
}

\author{
Carlos Toledo-Hernández ${ }^{\text {Corresp.., }}{ }^{1}$, Claudia P Ruiz-Diaz ${ }^{2}$, Liz Diaz ${ }^{3}$, Vanessa Santiago-Cárdenas ${ }^{4}$, Derick N \\ Rosario-Berrios $^{3}$, Derek M Garcia-Almedina ${ }^{3}$, Loretta M Roberson ${ }^{5}$ \\ 1 Sociedad Ambiente Marino SAM, San Juan, Puerto Rico \\ 2 Department of Environmental Science, University of Puerto Rico, San Juan, Puerto Rico \\ 3 Department of Chemistry, University of Puerto Rico, San Juan, Puerto Rico \\ 4 Department of Biology, University of Puerto Rico, San Juan, Puerto Rico \\ 5 Marine Resources Program, Marine Biological Laboratory, Falmouth, MA, United States \\ Corresponding Author: Carlos Toledo-Hernández \\ Email address: cgth0918@gmail.com
}

Background: The roles of gorgonian sclerites as structural components and predator deterrents have been widely studied. Yet, their role as barriers against microbes has only recently been investigated, and even less is known about the diversity and roles of the chemical compounds associated with sclerites. Methods: Here, we examine the semivolatile organic compound fraction (SVOCs) associated with sclerites from healthy and diseased Gorgonia ventalina sea fan corals to understand their possible role as a stress response or in defense of infection. We also measured the oxidative potential of compounds from diseased and healthy $G$. ventalina colonies. Results: The results showed that sclerites harbor a great diversity of SVOCs. Overall, 70 compounds were identified, the majority of which are novel with unknown biological roles. The majority of SVOCS identified exhibit multiple immune-related roles including antimicrobial and radical scavenging functions. The free radical activity assays further confirmed the anti-oxidative potential of some these compounds. The anti-oxidative activity was, nonetheless, similar across sclerites regardless of the health condition of the colony, although sclerites from diseased sea fans display slightly higher anti-oxidative activity than the healthy ones. Discussion: Sclerites harbor great SVOCs diversity, the majority of which are novel to sea fans or any other corals. Yet the scientific literature consulted showed that the roles of compounds found in sclerites vary from antioxidant to antimicrobial compounds. However, this study fell short in determine the origin of the SVOCs identified, undermining our capacity to determine the biological roles of the SVOCs on sclerites and sea fans. 
1 Comparison of chemical compounds associated with sclerites from healthy and diseased sea

2 fan corals (Gorgonia Ventalina).

3 Carlos Toledo-Hernández ${ }^{1}$, Claudia P. Ruiz-Diaz ${ }^{1,2}$, Liz M. Díaz-Vázquez ${ }^{3}$, Vanessa Santiago ${ }^{4}$,

4 Derick N. Rosario-Berrios ${ }^{3}$, Derek M. García-Almedina ${ }^{3}$, Loretta M. Roberson ${ }^{5}$.

51 Sociedad Ambiente Marino (SAM), San Juan, Puerto Rico

62 Department of Environmental Science, San Juan, Puerto Rico

73 Department of Chemistry, University of Puerto Rico, San Juan, Puerto Rico

84 Department of Biology, University of Puerto Rico San Juan, Puerto Rico

95 Marine Biological Laboratory, Woods Hole, MA USA

10 Corresponing author: Carlos Toledo-Hernández

11 Sociedad Ambiente Marino (SAM), PO Box 22158, San Juan, Puerto Rico 00931

12 e-mail address: cgth0918@gmail.com 
14 Background: The roles of gorgonian sclerites as structural components and predator deterrents

15 have been widely studied. Yet, their role as barriers against microbes has only recently been

16 investigated, and even less is known about the diversity and roles of the chemical compounds

17 associated with sclerites.

18 Methods: Here, we examine the semi-volatile organic compound fraction (SVOCs) associated

19 with sclerites from healthy and diseased Gorgonia ventalina sea fan corals to understand their

20 possible role as a stress response or in defense of infection. We also measured the oxidative

21 potential of compounds from diseased and healthy G. ventalina colonies.

22 Results: The results showed that sclerites harbor a great diversity of SVOCs. Overall, 70

23 compounds were identified, the majority of which are novel with unknown biological roles. The

24 majority of SVOCs identified exhibit multiple immune-related roles including antimicrobial and

25 radical scavenging functions. The free radical activity assays further confirmed the anti-oxidative

26 potential of some these compounds. The anti-oxidative activity was, nonetheless, similar across

27 sclerites regardless of the health condition of the colony, although sclerites from diseased sea fans

28 display slightly higher anti-oxidative activity than the healthy ones.

29 Discussion: Sclerites harbor great SVOCs diversity, the majority of which are novel to sea fans

30 or any other corals. Yet the scientific literature consulted showed that the roles of compounds

31 found in sclerites vary from antioxidant to antimicrobial compounds. However, this study fell

32 short in determine the origin of the SVOCs identified, undermining our capacity to determine the

33 biological roles of the SVOCs on sclerites and sea fans.

\section{INTRODUTION}

35 Sea fans (Gorgonia sp.) are one of the top competitors for space within Caribbean coral reefs

36 ecosystems. Similar to their relatives, the scleractinian corals, sea fans have suffered several 
37 environmental disturbances such as aspergillosis disease outbreaks (a fungal infection caused by

38 the saprophytic fungus Aspergillus sydowy) that seriously compromised the viability of many

39 populations across the Caribbean during the 1990s (Smith et al., 1996; Nagelkerken et al., 1997;

40 Geiser et al., 1998; Kim et al., 2004). Yet, in contrast to the scleractinian, sea fans have overcome

41 these disturbances and continue to thrive. In fact, gorgonians are the prevailing corals in many

42 reefs formerly dominated by scleractinian corals. Their relative success is provided in part, by

43 their strong immune defenses, which have allowed gorgonians to maintain their internal

44 homoeostasis and health (Ruiz-Diaz et al., 2013; Sabat \& Toledo-Hernández, 2015).

45 Gorgonians have a rather diverse repertory of defensive mechanisms to cope and respond to 46 disturbances, both abiotic and biotic (Toledo-Hernández \& Ruiz-Diaz 2014; Ruiz-Diaz et al., 47 2016). For instance, to respond to pathogen infection, gorgonians are equipped with chemical 48 pathways such as the melanin cascade that prevent or reduce the pathogen dissemination 49 throughout the host tissue (Petes et al., 2003; Mydlarz et al., 2008). Concomitant to this response, 50 gorgonians have the ability to activate the production of peroxidase enzymes, which induce the 51 production of reactive oxygen species with cytotoxic roles and cellular signaling (Mydlarz \& 52 Harvell, 2007). Furthermore, gorgonians are also characterized for their diverse production of

53 secondary metabolites, many of which are thought to be immune-related compounds due to their 54 anti-predation and microbial properties (Harvell, Fenical \& Green, 1988; Kim, 1994; Jensen et 55 al., 1996; Smith et al., 1996; Geiser et al., 1998; Kim et al., 2000a, 2000b, Alker et al., 2004).

56 Gorgonians also have sclerites, which are minute skeletal elements mainly composed of calcium 57 carbonate surrounding an organic matrix made up primarily of glycoproteins, spread throughout 58 the gorgonians' epidermis, mesoglea, and axial skeleton (Kingsely \& Watabe, 1982, 1984; 59 Harvell \& Suchanek, 1987, Van Alstyne \& Paul, 1992). Sclerites are thought to have multiple 60 defensive roles. For instance, sclerites provide structural support to gorgonians by reducing the 61 elasticity and stiffness of the axial skeleton against water motion (Koehl, 1982; Lewis \& Willis, 62 1991). In addition, sclerites play a role in deterring predation from gastropods and reef fishes 63 (Harvell, Fenical \& Greene, 1988; Van Alstyne \& Paul, 1992; Koh et al., 2000). Furthermore, the 64 purpling of sclerites (i.e., darkening of sclerites through the accumulation of pigments; Leverette 65 et al., 2008) has also been linked to defensive mechanisms against several biological threats 66 (Petes et al., 2003; Mydlarz \& Harvell, 2007; Mydlarz et al., 2008). 
67 Yet, the role of sclerites as chemical barriers against microbes has only recently been

68 investigated. For instance, Toledo-Hernández et al., (2016) showed that sea fan sclerites treated

69 with acetone and placed on top of the surfaces of culture media as to block the entrance of

70 microbes, were less effective at delaying the crossing and further colonization of fungi in the agar

71 than sclerites not treated with any solvent. However, no screening of chemical compounds in

72 sclerites was conducted in that study. In fact, studies devoted to surveying the chemical

73 compounds found in gorgonian sclerites are rather scarce, with only a few of them describing the

74 chemical composition of the core of sclerites (Kingsley \& Watabe, 1982, 1984; Kingsley et al.,

75 1990). Here we perform for the first time, a screening of the semi volatile organic compounds

76 (SVOCs) fraction found in sclerites from healthy and diseased G. ventalina colonies.

77 Furthermore, we performed a scientific literature survey of the SVOCs found in sclerites to

78 determine their potential biological roles. Finally, we conducted radical scavenging activity

79 assays to examine the oxidative potential of chemical compounds associated with sclerites from

80 healthy and diseased fans.

\section{METHODS}

\section{Tissue collection and sclerite isolation}

83 Sclerites used for this study were isolated from ten healthy and ten diseased Gorgonia ventalina 84 colonies located at a depth of 1.5-2.0 m from El Escambrón beach, San Juan, Puerto Rico

85 (18'28'00' $\mathrm{N}, 66^{\circ} 05^{\prime} 12^{\prime}$ 'W). The tissue samples were collected under permit 2012-IC-086 issued

86 to Claudia P. Ruiz Diaz, University of Puerto Rico (UPR) Rio Piedras campus, given by the

87 Puerto Rico Department of Natural Resources, Commonwealth of Puerto Rico. Healthy colonies

88 showed neither lesions nor tissue purpling, whereas diseased colonies showed at least one lesion

89 usually overgrown by algae and surrounded by a ring of purple tissue. Previous studies have used

90 the aforementioned pathology to diagnose algal tumor affliction, sea fan aspergillosis, as well as

91 competitive interactions between inter and conspecific individuals (Morse et al., 1977; Smith et

92 al., 1996; Alker et al., 2004). However, since we performed no microbiological or histological

93 analyses to determine the precise etiology of the injured tissue collected for this study, we

94 avoided the use of any term that could be associated with the afflictions previously described for

95 sea fans. One tissue fragment approximately $4 \mathrm{~cm}^{2}$ was cut from the edge of each healthy fan

96 (hereafter $\mathrm{HH}$ ). In diseased fans, $2 \mathrm{~cm}^{2}$ samples were cut from both healthy tissue at the edge of

97 the fan (healthy-diseased or HD) as well as from the diseased area (diseased-diseased or DD).

98 Fragments were placed individually in $50 \mathrm{~mL}$ centrifuge tubes and brought to the laboratory on 
99 ice. Once in the laboratory, each fragment was further cut into smaller fragments of $2-3 \mathrm{~cm}^{2}$ in

100 size and placed in $20.0 \mathrm{~mL}-$ sterilized leveled vials filled with $16.0 \mathrm{~mL}$ of distilled water. Then, to

101 disassociate sclerites from the soft tissue matrix, vials were vortexed at room temperature,

102 sonicated for $5 \mathrm{~min}$, and then allowed to settle for approximately $4 \mathrm{hrs}$. This procedure was

103 repeated over a period of 5-7 days to minimize impacts on the structure of the sclerites. After

104 disassociated, sclerites were rinsed several times with distilled water, individually transferred to

105 clean $55 \mathrm{~mm}$ Pyrex petri dishes, and dried at $35^{\circ} \mathrm{C}$ for $72 \mathrm{hrs}$.

\section{Gas chromatography-mass spectrometry analysis}

107 From each dried sclerite sample, $0.10 \mathrm{~g}$ were grounded in a clean porcelain mortar and the

108 homogenized powder was transferred to a $1.5 \mathrm{~mL}$ micro-test tube with $1 \mathrm{~mL}$ of acetone. Each

109 tube was vortexed and centrifuged at 6,000 rpm for $5 \mathrm{~min}$. Then, $1.5 \mathrm{~mL}$ of the resulting extract

110 from each sample was filtered and transferred without introducing air bubbles to clean amber

111 vials (32 x12 mm). Afterward, samples were purged with nitrogen to remove dissolve oxygen and

112 then septum caps were fitted to each vial and these were inverted to ensure no headspace was

113 visible and finally, vials were hermetically sealed and not opened until analyzed to preserve the

114 solution. Prior to injecting the solvent used for the extraction, reagents, glassware and other

115 samples processing hardware were blank tested to ensure these materials will not add artifacts to

116 the sclerite extracts analyses. Then, vials with sclerite extracts were placed in an Agilent 7890A

117 gas chromatograph (GC) coupled to an Agilient $5975 \mathrm{C}$ mass-selective detector for splitless

118 injection. Because removing a sample aliquot from the vials may compromise the integrity of the

119 sample, multiple aliquots were injected to allow for the screening and re-analysis of the samples.

120 The injection temperature was $250^{\circ} \mathrm{C}$. Separation of samples was performed using a fused silica

121 capillary column $(\mathrm{SLB} \AA-5 \mathrm{~ms} 30 \mathrm{~m} \times 0.32 \mathrm{~mm} \times 0.25 \mu \mathrm{m}$ film thickness; Supelco, Bellefonte,

122 PA). The initial column temperature was held at $70^{\circ} \mathrm{C}$ for $1 \mathrm{~min}$, and then increased by $8{ }^{\circ} \mathrm{C} \mathrm{min}{ }^{-}$

$123{ }^{1}$ until reaching $270{ }^{\circ} \mathrm{C}$, where it was held for $3 \mathrm{~min}$, for a total run time of $29 \mathrm{~min}$ per sample.

124 Ultrapure helium at constant-flow of $1.2 \mathrm{~mL} \mathrm{~min}^{1}$ was used as the carrier gas. Analysis of the

125 generated chromatograms was performed using the AMDIS version 2.7/NIST version 2.0

126 computer program and the criteria for selection in the analysis for the screening compounds were:

127 (1) R- match $>800$; (2) $\mathrm{S} / \mathrm{N}>15$; and (3) peak areas $>1000$. Compound identification was

128 confirmed through the use of NIST library appropriated standards and retention time index

129 (http://www.nist.gov/srd/nistla.cfm). To determine the potential biological roles of each of the 
130 detected compounds, a scientific literature review using the IUPAC names of each compound was 131 conducted.

\section{Free radical scavenging assay}

133 Free radical scavenging activity of sclerite extracts was estimated using 1,1,-diphenyl-2-

134 picrylhydrazyl (DPPH) (MacDonald-Wisk, Wood \& Garg, 2006). Briefly, $0.10 \mathrm{~g}$ of homogenized

135 powder not previously used from each of the sclerite samples was placed into labeled and clean

$13650 \mathrm{~mL}$ centrifuge tubes filled with $5.0 \mathrm{~mL}$ methanol. Then, each tube was vortexed for $10 \mathrm{sec}$,

137 placed in a water bath at $40{ }^{\circ} \mathrm{C}$ for $40 \mathrm{~min}$, and sonicated afterward for $30 \mathrm{~min}$. The samples were

138 then centrifuged for $10 \mathrm{~min}(6,000 \mathrm{rpm})$ at $25^{\circ} \mathrm{C}$. Afterwards, $1.0 \mathrm{~mL}$ of the supernatant ("sclerite 139 extract") was transferred to a clean $50 \mathrm{~mL}$ centrifugal tube containing $5.0 \mathrm{~mL}$ methanol. Then, 1

$140 \mu \mathrm{L}$ of the sclerite extract and $39 \mu \mathrm{L}$ of DPPH $(0.09 \mathrm{mM})$ were added to a 96 -well microplate and

141 the absorbance of the each sample was recorded at 0,1,4 and 5 minutes and then every 5 minutes

142 for a one-hour period at $560 \mathrm{~nm}$ in a Thermo Scientific Multiscan FC spectrophotometer. Only

143 those samples with absorbances with absorbance $<2$ were used in the analysis. Scavenging

144 activity in this study was expressed as $\mathrm{IC}_{50}$, which represents the concentration of extracts

$145(\mathrm{mg} / \mathrm{mL})$ needed to inhibit $50 \%$ of the DPPH radicals. To calculate $\mathrm{IC}_{50}$ for each sclerite sample,

146 the percent inhibition of radical production $(\% \mathrm{I})$ was estimated using the following equation

147 (Mishra et al., 2012):

$$
\% \mathrm{I}=\left(\mathrm{A}_{\mathrm{i}}-\mathrm{A}_{\mathrm{f}}\right) \cdot 100 / \mathrm{A}_{\mathrm{i}}
$$

149 where $A_{i}$ and $A_{f}$ represent the initial and final absorbance, respectively. A linear regression 150 analysis was performed with extract concentration as the independent variable and \% $\mathrm{I}$ as the 151 dependent variable. Finally, the resulting linear regression equations with a correlation coefficient $152 \mathrm{R}^{2}>80 \%$ were used to estimate the $\mathrm{IC}_{50}$.

\section{Statistical analyses}

154 Nonmetric Multi Dimensional Scaling (nMDS) along with an Analysis of Similarity (ANOSIM)

155 with Bray-Curtis distances measurement were utilized to compare the composition of chemical

156 compounds among the sclerites from different tissues. We used nMDS ordination, achieved by

157 the metaMDS wrapper function from the package vegan in $\mathrm{R}$ version 3.2. The ordination was

158 applied such that the data was scaled down to two dimensions. 
159 For the analysis of free radical scavenging, a Kruskal-Wallis was performed to detect differences

160 between $\mathrm{IC}_{50}$ index from sclerites from different tissues. In this analysis, $\mathrm{IC}_{50}$ index was assigned

161 as the dependent variable and the origin of the sclerite was assigned as the independent variable.

162 Finally, a $\mathrm{Chi}^{2}$ test was conducted to determine statistical differences in the relative abundances

163 of alcohols, alkanes and alkenes and sclerite origin. In all analyses, P-value was fixed at 0.05.

164 Statistical analyses were performed using R version 3.2 (R Core Team, 2014). For the statistical

165 analyses, HD and DD samples from the same colony where considered independent and analyzed

166 accordingly. In modular organisms such as gorgonian corals, modules are semi-autonomous units.

167 Consequently, any particular stressors (abiotic or biotic) may trigger or have a differential

168 consequence in tissue subjected to different health states (Van Valen, 1978; Tuomi \& Vuorisalo, 169 1989).

170 RESULTS

\section{Semi-volatile organic compounds}

172 A total of 70 SVOCs were found in the sampled sclerites; $37 \%$ of these were identified from DD

173 sclerites, while $35 \%$ and $29 \%$ were identified from DH and $\mathrm{HH}$ sclerites, respectively. Yet, the

174 nMDS and ANOMIS analyses failed to group the chemical compounds according to their origin

175 (e.g., HH, HD and DD sclerites). This holds true even when compounds found only once or twice

176 across the samples were eliminated from the analysis.

177 In general, three major groups were identified: alcohols, alkanes and alkenes. When data was

178 organized based on sclerite origin, alcohols and secondarily alkanes were the most frequently

179 identified SVOCs in all samples, although the number of identified alkenes was higher in HD

180 sclerites (Figure 1). However, the $\mathrm{Chi}^{2}$ test analysis revealed no statistical differences between

181 alcohols, alkanes and alkenes and the sclerites origin. Furthermore, DD sclerites exhibited the

182 highest number of exclusive compounds with a total of 17 unique SVOCs, followed by HH and

183 HD sclerites with 15 and 8 unique SVOCs, respectively (Table S1; Figure 2). The remaining

184 SVOCs were either shared across all sclerites or between two distinct combinations of sclerites

185 (Figure 2).

186 Evidence from the scientific literature concerning the possible biological roles of the SVOCs

187 identified in sclerites was obtained for $44 \%$ the compounds. Most were associated with immune

188 related roles such as antimicrobials and antioxidants. Less represented roles were related to 
189 cytotoxic and apoptotic compounds, cell membrane components such as steroids and oxidized

190 steroids derivatives, and intermediate signaling molecules.

\section{Free radical scavenging assay}

192 Thirteen out of the 30 sclerites sampled tested had $\mathrm{R}^{2}>80 \%$ and thus were used for the free

193 radical scavenging assays. Of these, six samples were HH sclerites, whereas four and three were

194 DD and HD sclerite samples, respectively. The free radical scavenging $\mathrm{IC}_{50}$ ranged from $0.21 \mathrm{mg}$

195 dry extract/mL to $0.01 \mathrm{mg}$ dry extract/mL DPPH. Observed differences in antioxidant activity

196 among sclerites were not statistically different, however on average there was a trend for higher

197 values in $\mathrm{HH}$ and lowest in DD sclerites (Figure 3).

\section{DISCUSSION}

199 Overall, 70 SVOCs associated with sclerites were identified. The majority of compounds have 200 not been reported previously in corals and consequently little is known of their biological roles

201 (Table S1). Several of these SVOCs were common to all sclerites samples, whereas others were 202 found in two or exclusively in one of sclerite types (Table S1; Figure 2). Yet, no clusters between 203 the compounds and health states were formed, suggesting that the chemical composition of 204 sclerites is similar across the samples independent of the health state of the colony. Nonetheless, 205 the concentration of these compounds may vary among colonies with contrasting health state, but 206 our data do not provide sufficient details to validate or reject this argument.

207 On the other hand, the scientific literature surveyed revealed potential roles for some of the 208 compounds. For instance, some of the compounds identified in this study have been characterized 209 as free radical scavengers (Table S1). The oxidative analysis assays performed in this study, 210 which revealed that extracts from the three sclerite origins exhibit antioxidant activity, further 211 confirms this fact.

212 Antioxidant production in gorgonians is thought to have mitigating roles during several immune 213 responses including phagocytosis, peroxidase enzymatic activity, and melanization (Olano \& 214 Bigger, 2000; Midlarz \& Harvell, 2007). These immune responses produce reactive oxygen 215 species (ROS) and other free radical molecules, inducing oxidative stress in the coral.

216 Consequently, to counteract this oxidative stress, sea fans have developed regulatory systems 217 such as increased production of non-enzymatic antioxidant scavengers, which neutralize the 
218 potential harmful impact of ROS and other free radical molecules (Yost, Jones \& Mitchelmore, 219 2010; Shahbudin et al., 2011).

220 Antioxidant capacity in corals has also been linked to thermal stress. Several studies have 221 reported that corals under thermal stress exhibit higher antioxidant potential than those under 222 normal temperature conditions (Downs et al., 2002; Griffin \& Bhagooli, 2004). In fact, over223 expression of genes involved in the oxidative-stress response has been reported to increase in 224 acroporids after they have undergone thermal stress (Császá, Senaca \& Oppen, 2009).

225 Alternatively, microbes associated with sea fans, both prokaryotes and eukaryotes, may be 226 producing the antioxidant compounds found in sclerites. In the case of eukaryotes such as 227 zooxanthellae for instance, antioxidants may be synthesized as a mitigating mechanism against 228 ROS produced during photosynthesis (Foyer and Shigeoka, 2011).

229 Compounds known to have antimicrobial properties such as alcohols and esters were also 230 identified in sclerites (Table S1). Many of these compounds have been isolated from terrestrial 231 plants. Nonetheless, the fact that gorgonians produce chemical compounds with antimicrobial 232 activities is not surprising. Multiple culture-based studies using extracts from several gorgonians 233 species have revealed the antimicrobial potential of these extracts (Kim1994, 2000; Jensen et al., 234 1996; Alker, Smith \& Kim, 2001; Alker et al., 2004; Ward et al., 2007). Nonetheless, in this 235 study, no relationship could be established between the origin of compounds (i.e., diseased or

236 healthy corals) and their microbial roles, as the majority of the potential roles of the compounds

237 could not be obtained from the scientific literature. Many of these compounds could be 238 precursors or intermediaries of potentially biologically relevant molecules that were trapped 239 within the sclerites during their formation. If indeed some of the compounds isolated from 240 sclerites are precursors of biologically active molecules, as well as environmental cues or internal 241 stressors, sclerites could be used as archives of metabolic pathways or past climatic and biotic 242 stress events.

\section{CONCLUSIONS}

244 Sclerites harbor a great SVOC diversity, the majority of which are novel to sea fans or any other 245 corals. However, a major drawback of the study is our inability to determine the origins of these 246 SVOCs. For instance, it is uncertain which SVOCs, if any, were synthetized by microbes 247 associated with sea fans. On the other hand, certain compounds may be derivatives from other 
248 compounds. For instance, 1-undercene, 9 methyl, could be a derivative of other compounds such

249 as alcohols which have undergone esterification reactions to form esters that are import fractions

250 of lipids and steroids of living cells. In either case, not knowing the origin of the SVOCs hinder

251 our capacity to understand the underlying mechanism of their biological function. However, as

252 research progresses and our understanding of sclerite formation is improved, coupled with the

253 identification of other chemical compounds using different extraction solvents (polar and non-

254 polar),

255 our understanding of the roles the chemical compounds from sclerites and the corals in general

256 will improve. Yet, the present study represents a necessary first step in that process.

\section{Acknowledgements}

258 We like to express our gratitude to Alberto M. Sabat for his friendly review.

\section{REFERENCES}

260 Alker P, Smith GW, Kim K. 2001. Characterization of Aspergillus sydowii (Thom et Church), a

261 fungal pathogen of Caribbean sea fan corals. Hydrobiology 460:105-111.

262 Alker AP, Kiho K, Dube DH, Harvell CD. 2004. Localized induction of a generalized response

263 against multiple biotic agents in Caribbean sea fans. Coral Reefs 23:397-405.

264 Császár NBM, Seneca FO, van Oppen MJH. 2009. Variation in antioxidant gene expression in

265 the scleractinian coral Acropora millepora under laboratory thermal stress Marine Ecology

266 Progress Series 392:93-102.

267 Downs, CA, Fauth JE, Halas JC, Dustan P, Bemiss J, Woodley CM. 2002. Oxidative stress and

268 seasonal coral bleaching. Free Radical Biology and Medicine 33:533-543.

269 Foyer CH, Shigeoka S. 2011. Understanding oxidative stress and antioxidant function to enhance 270 photosynthesis. Plant Physiology 155:93-100.

271 Geiser DM, Taylor JW, Ritchie KB, Smith GW. 1998. Cause of sea fan death in the West Indies. 272 Nature 394:137-138.

273 Griffin PS, Bhagooli R. 2004. Measuring antioxidant potential in corals using the FRAP assay. 
274 Journal of Experimental Marine Biology and Ecology 302:201-211.

275 Harvell CD, Suchanek TH. 1987. Partial predation on tropical gorgonians by Cyphoma gibbosum 276 (Gastropoda). Marine Ecology Progress Series 38:37- 44.

277 Harvell CD, Fenical W, Greene CH. 1988. Chemical and structural defenses of Caribbean 278 gorgonians (Pseudopterogorgia spp.). I. Development of an in situ feeding assay. Marine 279 Ecology Progress Series 49:287-294.

280 Jensen PR, Harvell CD, Wirtz K, Fenical W. 1996. Antimicriobial activity of extracts of 281 Caribbean gorgonian corals. Marine Biology 125:411-419.

282 Kim K. 1994. Antimicrobial activity in gorgonian corals (Coelenterata, Octocoralllia). Coral 283 Reef. 13(2):75-80.

284 Kim K, Harvell CD, Smith GW, Merkel SM. 2000a. Fungal disease resistance of Caribbean sea 285 fan corals (Gorgonia spp.). Marine Biology 136:259-267.

286 Kim K, Kim PD, Alker AP, Harvell CD. 2000b. Chemical resistance of gorgonian corals against 287 fungal infections. Marine Biology 137:393-401.

288 Kim K and Harvell CD. 2004. The rise and fall of a six-year coral fungal epizootic. American 289 Naturalist 164:S52-S63.

290 Kingsley R, Watabe N. 1982. Ultrastructure invitation of spicule formation in the gorgonian 291 Leptorgorgia virgulata (Lamarck) (Coelenterata: Gorgonacea). Cell and Tissues Research 223: 292 325-334.

293 Kingsley R, Watabe N. 1984. Synthesis and transport of the organic matrix of the spicules in the 294 gorgonian Leptogorgia virgulata (Coelenterata: Gorgonacea). An autoradiographic investigation. 295 Cell and Tissues Research 235:533-538.

296 Kingsley RJ, Tsuzak m, Watabe N, Gerald 1, Mechanic GL. 1990. Collagen in the spicule organic 297 matrix of the gorgonian Leptogorgia virgulata. Biological Bulletin 179:207-213. 
298 Koehl MAR. 1982. Mechanical design of spicule-reinforced connective tissue: stiffness. Journal 299 of Experimental Biology. 98:239-267.

300 Koh LL, Goh NKC, Chou LM, Tan YW. 2000. Chemical and physical defenses of Singapore 301 gorgonians (Octocorallia: Gorgonacea). Journal of Experimental Marine Biology and Ecology. 302 251:103-115.

303 Lewis, JC, Wallis, EV. 1991. The function of surface sclerites in gorgonians (Coelenterata, 304 Octocorallia). Biological Bulletin.18:275-288.

305 Leverette CL, Warren M, Smith MA, Smith GW. 2008. Determination of carotenoid as the purple 306 pigment in Gorgonia ventalina sclerites using Raman microscopy. Spectrochimica Acta Part A. 307 69:1058-1061.

308 MacDonald LK, Wood LG, Garg M. 2006. Methodology for the determination of biological 309 antioxidant capacity in vitro: a review. Science of Food and Agriculture. 86:2046-2056.

310 Mishra K, Ojha H, Nabo Kumar Chaudhury NK. 2012. Estimation of antiradical properties of 311 antioxidants using DPPH assay: A critical review and results. Food Chemistry. 130:1036-1043 312 DOI10.1016/j.foodchem.2011.07.127

313 Morse DE, Morse ANC, Duncan H. 1997. Algal tumor in the Caribbean sea fan, Gorgonia 314 ventalina. Proceeding of the 3th Third International Coral Reef Symposium, Miami Florida, 623315629.

316 Mydlarz LD and Harvell CD. 2007. Peroxidase activity and inducibility in the sea fan coral 317 exposed to a fungal pathogen. Comparative Biochemistry Physiology, Part A. 146:54-62.

318 Mydlarz LD, Holthouse SF, Pters EC, Haverl CD. 2008. Cellular responses in sea fan corals: 319 Granular amoebocytes react to pathogen and climate stressors. PloS ONE.

320 10.1371/journal.pone.0001811.

321 Nagelkerken IK, Smith GW, Bonair K, Bush P, Garzón-Ferriera J, Botero L, Gayle P, Harvell 322 CD, Heberer C, Kim K, Petrovic C, Pors L, Yoshioka P. 1997. Widespread disease in Caribbean 323 sea fans: II. Patterns of infection and tissue loss. Marine Ecology Progress Series 160:255-263.

324 Olano CT and Bigger CH. 2000. Phagocytic activities of the gorgonian coral Swiftia exserta. 
326 Petes LE, Harvell CD, Peters EC, Webb MAH, Mullen KM. 2003. Pathogens compromise 327 reproduction and induce melanization in Caribbean sea fans. Marine Ecology Progress Series $328 \quad 264: 167-171$.

329 Sabat AM and Toledo-Hernández C. 2015. Viability of sea fan population impacted by disease:

330 Recruitment versus Incidence. Journal of Marine Biology 10.1155/2015/987060.

331 Shahbudin S, Deny S, Zakirun AMT, Haziyamin TAH, Akbar John B, Taher M. 2011.

332 Antioxidant properties of soft coral Dendronephthya sp. International Journal of Pharmacology 333 7:263-267.

334 Smith GW, Ives, LD, Nagelkerken IA, Ritchie KB. 1996. Caribbean sea-fan mortalities. 335 Nature.383:487.

336 R Core Team. 2014. R: A language and environment for statistical computing. R Foundation for 337 statistical Computing, Vienna, Austria. URL http://www.R-projct.org/.

338 Ruiz-Diaz CP, Toledo-Hernández C, Sabat AM, Marcano M. 2013. Immune response to a 339 pathogen in corals. Journal of Theoretical Biology 332:141-148.

340 Ruiz-Diaz CP, Toledo-Hernández C, Mercado-Molina A, Sabat AM. 2016. Scraping and 341 extirpating: two strategies to induce recovery of diseased Gorgonia ventalina sea fans. Marine 342 Ecology 37: 336-343.

343 Tuomi J and Vuorisalo T. 1989. What are the units of selection in modular organisms? Oikos $344 \quad 54: 227-233$.

345 Toledo-Hernández C and Ruiz-Díaz CP. 2014. The immune response of corals. Invertebrate 346 Survival Journal 11:319-328.

347 Toledo-Hernández C, Ruiz-Díaz CP, Paniagua R, Roberson L, Ramírez-Camejo L, Sabat AM, 348 Bayman P. 2016. The role of sclerites in the defense against pathogens of the sea fan Gorgonia 349 ventalina (Octocorallia). Journal of Experimental Marine Biology and Ecology 483:20-24.

350 Ward JR, Rypien KL, Bruno JF, Harvell, CD, Jordán-Dahlgre E, Mullen KM, Rodríguez- 
351 Martínez RE, Sánchez J, Smith G. 2007. Coral diversity and disease in Mexico. Diseases of 352 Aquatic Organisms 69:23-31.

353 Yost DM, Jones RJ, Mitchelmore CL. 2010. Alterations in dimethylsulfoniopropionate (DMSP) 354 levels in the coral Montastraea franksi in response to copper exposure. Aquatic Toxicology 355 98:367-373.

356 Van Alstyne KL, Paul VJ. 1992. Chemical and structural defenses in the sea fan Gorgonia 357 ventalina: effects against generalist and specialist predators. Coral Reefs 11:155-159.

358 Van Valen L. 1978. Arborescent animals and other colonids. Nature 276:318.

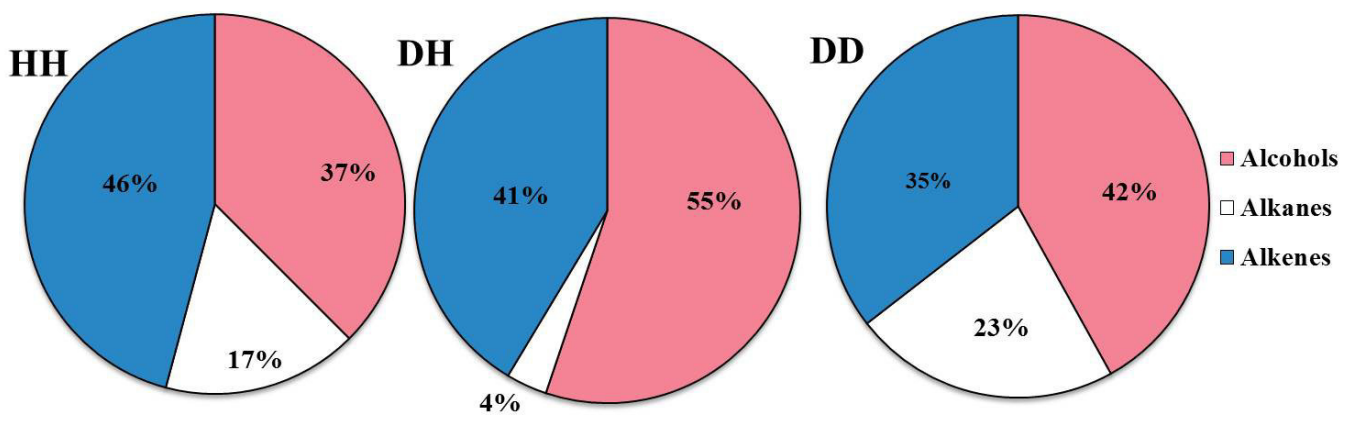

359 Figure 1. Percentages of the main functional chemicals in sclerites from healthy sea fans $(\mathrm{HH})$, 360 from healthy tissue from diseased sea fans (HD), and diseased tissue from diseased sea fans 361 (DD). 


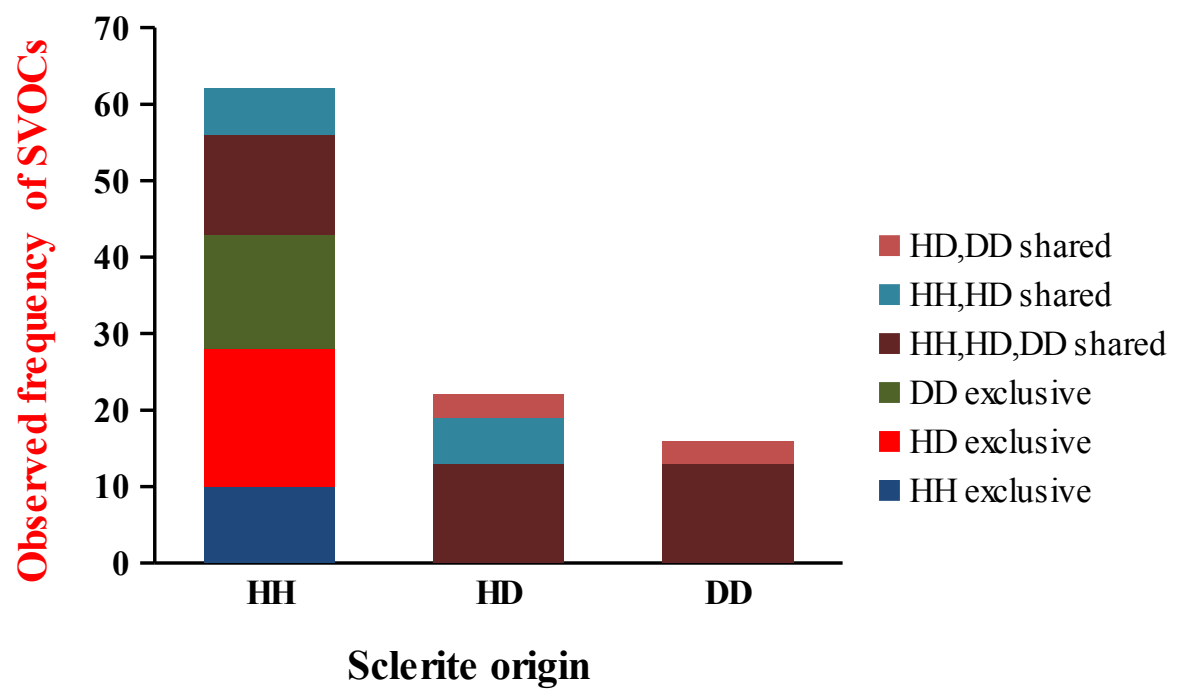

362 Figure 2. Number of volatile organic compounds (VOCs) in sclerites from healthy sea fans (HH), 363 healthy tissue from diseased sea fans (HD), and diseased tissue from diseased sea fans (DD). 


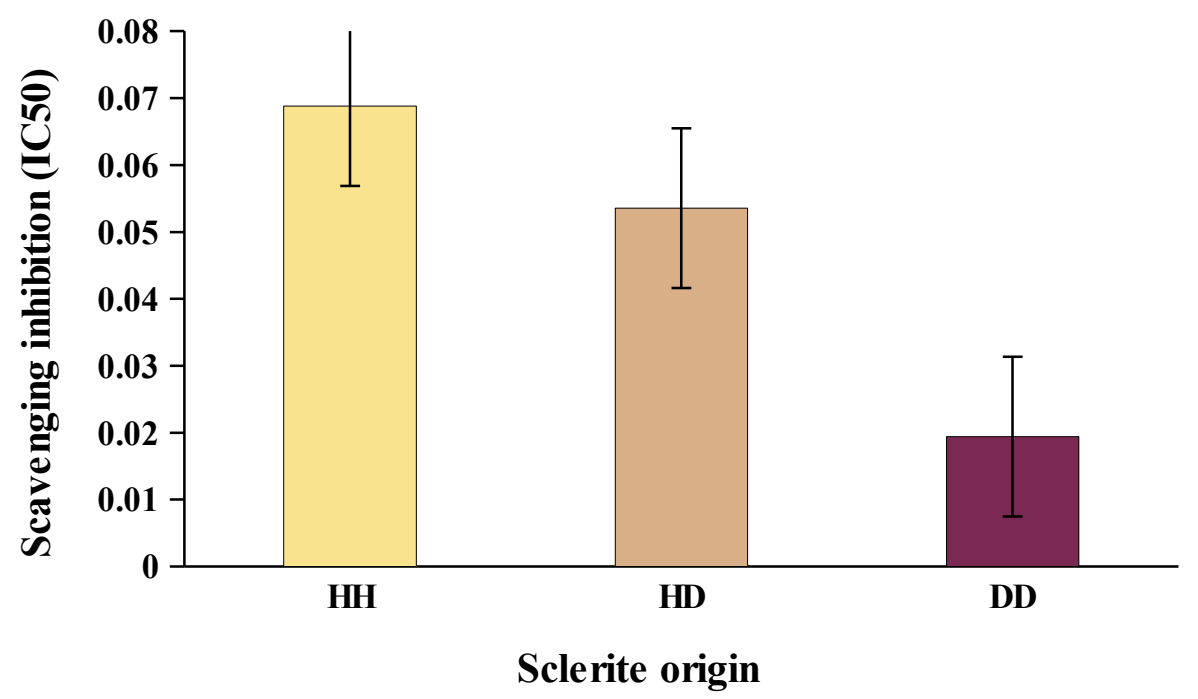

364 Figure 3. Average of free radical scavenging analysis expressed as $\mathrm{IC}_{50}$ of sclerites from healthy 365 sea fans (HH), healthy tissue from diseased fans (HD) and diseased tissue from diseased fans 366 (DD). Bars denote standard errors. 